\title{
AQUELE UM ESTUDO TOPONÍMICO DO PELOURINHO
}

Joana Angélica Santos Lima (UFMG)

\section{Introdução}

O topônimo constitui-se objeto de estudo da Toponímia, parte da Onomástica que visa investigar os nomes próprios de lugar. Os primeiros estudos dessa ciência como corpo disciplinar sistematizado partiram do francês Augusto Longonon por volta de 1878. Conforme Dick (1990), uma investigação toponímica permite descobrir a origem do significado etimológico, ler o que a palavra esconde sob sua aparência gráfica, conhecer fatos históricos e situações geográficas. Em outras palavras, fazer um estudo toponímico é desmistificar a história de um povo, visto que os nomes de lugares trazem sempre no bojo de sua história um "emaranhado" de particularidades que configuram a identidade sócio-cultural de uma determinada comunidade, refletido no processo de sua nomeação. Tudo isto é possível porque:

Os topônimos conservam tradições e costumes de uma comunidade na medida em que se utilizam de sua cultura lingüística para nomear os acidentes geográficos. Seabra (2004).

Com base no poder dos topônimos de conservar tradições é que neste trabalho pretende-se investigar e classificar os principais nomes de ruas, praças e largos que constituem o Pelourinho - mais antigo bairro de Salvador - no intuito de elucidar suas respectivas motivações designativas. Serão analisados apenas os principais topônimos em decorrência da limitação dos dados informativos pesquisados. A classificação desses signos toponímicos será efetivada mediante as taxionomias propostas por Dick (1990).

Desenvolver esse tema à luz da Toponímia justifica-se no desejo de contribuir com os diversos estudos já desenvolvidos acerca do mesmo, uma vez que por possuir um vasto campo de estudo, constitui-se objeto de inspiração para muitas pesquisas nas variadas disciplinas. 
Este trabalho encontra-se organizado da seguinte forma: na seção 1, apresenta-se um breve relato sobre a história do surgimento do bairro Pelourinho; na seção 2, ilustra-se a ficha lexicográfica do topônimo "Pelourinho", contemplando, principalmente, sua classificação taxionômica, bem como sua etimologia; na seção 3, estão expostas a classificação dos topônimos do Pelourinho, segundo as taxionomias propostas por Dick (1990), e, também, a ficha lexicográficas desses topônimos em estudo, onde se tenta ilustrar brevemente a motivação de cada nome designativo dos mesmos; na seção 4, trata-se das considerações finais delineadas acerca da pesquisa.

\section{História do Pelourinho}

O termo pelourinho era utilizado para nomear uma coluna de madeira ou pedra erguida em praça pública para castigar criminosos. Idealizado na Europa na Idade Média, esse hábito foi trazido para o Brasil pelos portugueses no período da fundação da cidade de Salvador, assim nomeada para homenagear Jesus Cristo. Fundada por Tomé de Souza em 1549, por questões convencionais, a cidade "fortaleza" foi construída na parte mais alta da região em frente ao porto, protegida por extensas e estratégicas muralhas, onde se construíram sofisticados casarões, sobrados e igrejas, inspirados na arquitetura barroca por volta do século XVII.

Inicialmente, no Brasil, o pelourinho era construído apenas nas fazendas dos senhores de engenhos para castigar seus escravos. Entretanto, para demonstrar autoridade à população, os senhores de escravos juntamente com as demais autoridades da região resolveram construí-lo no centro da cidade, em frente à Casa da Câmara e da Cadeia - atual Câmara de Vereadores - onde não apenas escravos, mas também criminosos passaram a ser punidos publicamente. No início do século XVIII, o mesmo foi transferido para o Terreiro de Jesus, porém a pedido dos jesuítas foi removido para a praça do Mercado - então praça Castro Alves. Finalizada a escravatura no país, mais tarde, em meio a comemorações da 
Independência Brasileira, o compreendido símbolo da opressão e da injustiça foi derrubado por manifestantes.

O pelourinho passou a ser ponto de referência da cidade, nomeando assim, com o passar dos anos, o mais antigo bairro soteropolitano, a saber o Pelourinho, o qual até o início do século XX abrigou as famílias aristocratas tradicionais, que em busca de um novo estilo de vida se mudaram para o corredor da Vitória. A partir de então, surge a história do maior e mais famoso ponto de prostituição e de tráfico de drogas da cidade, cuja trajetória perdurou por muitas décadas. Posteriormente, o valioso patrimônio foi tombado pela Unesco (Organização das nações Unidas para a Educação, Ciência e Cultura) e submetido, em 1991, a um processo de reabilitação que resultou na origem de um grande centro cultural.

Localizado no Centro Histórico de Salvador, o Pelourinho é um dos mais ricos e significativos cartão postal da cidade, assim reconhecido não apenas pela sua história, mas também pela bela paisagem oferecida e pela sua riqueza agrupada no conjunto arquitetônico barroco-português constituído aproximadamente de 354 construções dos séculos XVII, XVIII e XIX. Riqueza esta que compõe sua pequena área geográfica compreendida entre o Terreiro de Jesus e a Igreja do Passo. Do seu pequeno espaço, atualmente, fazem parte a Igreja do Carmo, Igreja de São Francisco, Fundação Casa de Jorge Amado, Escola de Medicina, Museu da Cidade, Museu Abelardo Rodrigues, Teatro Miguel Santana, Museu Knoph e sede do grupo Afoxé Filhos de Ghandhy e da Banda Olodum, além dos diversos bares, lojas, galerias de arte e restaurantes também distribuídos em suas ruas, praça e largos. 
3- Ficha do Topônimo Pelourinho

\begin{tabular}{|c|c|}
\hline Localização/ Município & $\begin{array}{l}\text { No Centro Histórico ao lado } \\
\text { norte de Salvador }\end{array}$ \\
\hline Topônimo & Pelourinho \\
\hline A.G & Bairro (físico/humano) \\
\hline Taxionomia & Ergotopônimo /Sociotopônimo \\
\hline Estrutura Morfológica & Nome (substantivo, singular) \\
\hline Histórico & $\begin{array}{l}\text { Parte Central de Salvador }< \\
\text { Pelourinho }\end{array}$ \\
\hline Etimologia / Entrada Lexical & $\begin{array}{l}\text { Pelourinho }- \text { o fr. Pilori, } \\
\text { francização do lat. medieval pilorium, } \\
\text { provavelmente derivado do lat. Pila } \\
\text { "pilar" com o sifixo "orium" para } \\
\text { exprimir que se permanecia aí durante } \\
\text { algum tempo. (Bloch - Warburg). Em } \\
1550 \text { "Rua dereita dos moinhos que } \\
\text { vai ter a rua da Graça defronte o } \\
\text { pelovrinho". No Arquivo Histórico de } \\
\text { Portugal I, p. } 75 . \text { (Dicionário } \\
\text { etimológico da língua portuguesa - José } \\
\text { Pedro Machado. } \\
\text { Pelourinho/peloirinho. } \\
\text { s.m.Coluna de pedra ou madeira em } \\
\text { praça ou sítio público, junto da qual se } \\
\text { expunham e castigavam os criminosos. }\end{array}$ \\
\hline
\end{tabular}




\section{4- Topônimos do Pelourinho}

O pequeno espaço do mais antigo bairro de Salvador, o Pelourinho, é composto de três diferentes tipos de logradouros, a saber: ruas, praças e largos cujas designações nominativas expressam um pouco da formação histórica e cultural do povo baiano.

De acordo com Dick (1990), os topônimos podem ser motivados por taxionomias de natureza física (fitotopônimo, cardinotopônimo, cromotopônimo, zootopônimo, hidrotopônimo, etc) e/ou antropo-cultural: antropotopônimo, animotopônimo, axiotopônimo, hagiotopônimo, cronotopônimo, etc). Tomandose por base sua teoria, serão apresentadas, a seguir, a classificação taxionômica dos topônimos do Pelourinho e suas respectivas fichas lexicográficas.

\subsection{Classificação dos topônimos do Pelourinho}

\begin{tabular}{|r|l|l|}
\hline 01 & Nomes das Ruas & Classificação \\
\hline 02 & Rua do Bispo & antropotopônimo \\
\hline 03 & Rua Francisco Muniz & antropotopônimo \\
\hline 04 & Rarreto & \\
\hline 05 & Rua Gregónónio de Matos & axiotopônimo \\
\hline 06 & Rua Inácio Acioli & antropotopotopônimo \\
\hline 07 & Rua João de Deus & antropotopônimo \\
\hline 08 & Rua das Laranjeiras & fitotopônimo \\
\hline 09 & Rua Padre Agostinho & axitopônimo \\
\hline 10 & Rua Santa Isabel & hierotopônimo : hagiotopônimo \\
\hline 11 & Rua 12 de outubro & historiotopônimo \\
\hline 12 & Rua do Passo & hodotopônimo \\
\hline 13 & Praça Anchieta & axiotopônimo \\
\hline 14 & Largo do Carmo & hierotopônimo \\
\hline
\end{tabular}




\begin{tabular}{|r|c|c|}
\hline 15 & $\begin{array}{c}\text { Largo do Cruzeiro de São } \\
\text { Francisco }\end{array}$ & $\begin{array}{c}\text { hagiotopônimo. } \\
\text { hagiotopônimo. }\end{array}$ \\
\hline 16 & Largo de Pedro Arcanjo & antropotopônimo \\
\hline 17 & $\begin{array}{c}\text { Largo de Quincas Berro } \\
\text { D'Água }\end{array}$ & antropotopônimo \\
\hline 18 & Largo de Tereza Batista & antropotônimo \\
\hline 19 & Largo do Pelourinho & ergotopônimo \\
\hline 20 & Largo do Terreiro de & hierotopônimo : hagiotopônimo \\
\hline
\end{tabular}

\subsection{Fichas lexicográficas}

Rua Alfredo de Brito - A.G.: humano / rua. Taxionomia: antropotopônimo. Histórico: Rua Alfredo de Brito. Explicação: Em homenagem a Alfredo Thomé de Britto (1866-1909), o qual atuou como diretor da Faculdade de Medicina da Bahia entre 1901 a 1908.

Rua Francisco Muniz Barreto - A.G.: humano / rua. Taxionomia: antropotopônimo. Histórico: Rua Francisco Muniz Barreto. Explicação: Em homenagem ao professor e poeta baiano Francisco Muniz Barreto, cujo nome teve destaque na história brasileira por participar em 1797 da fundação da Academia dos Renascidos, associação literária onde se discutiam ideais iluministas e problemas sociais que afetavam a população.

Rua Frei Vicente - A.G.: humano / rua. Taxionomia: axiotopônimo. Histórico: Rua Frei Vicente. Explicação: Em homenagem a Vicente Rodrigo de Palha, frei baiano (provavelmente nascido em 1564) formado em Teologia e Cânones pela Universidade de Coimbra e autor da primeira obra denominada História do Brasil.

Rua Gregório de Matos - A.G.: humano / rua. Taxionomia: antropotôponimo Histórico: Rua Gregório de Matos. Explicação: Em homenagem 
ao poeta barroco brasileiro, Gregório de Matos, o qual em função de suas poesias satíricas tornou-se conhecido como "Boca do Inferno". Gregório nasceu em Salvador em 1613 e faleceu em 1695 em Recife.

Rua Inácio Acioli - A.G.: humano / rua. Taxionomia: antropotopônimo. Histórico: Rua Inácio Acioli. Explicação: Em homenagem a Inácio Acioli de Cerqueira e Silva, cronista-mor do Império, e autor de Memórias históricas e políticas da província da Bahia (1843) e Corografia ou descrição física, histórica e política da província de Grão Pará (1833).

Rua João de Deus - A.G.: humano / rua. Taxionomia: antropotopônimo. Histórico: Rua João de Deus. Explicação: Homenagem ao poeta e pedagogo português João de Deus (1830-1896), autor da Cartilha Maternal (1876), a qual continha um novo método de ensino de leitura.

Rua das Laranjeiras - A.G.: humano / rua. Taxionomia: fitotopônimo. Histórico: Rua das Laranjeiras. Explicação: Conta-se que nessa rua morava um padre que em cuja vida pessoal havia irregularidades. Desconfiando de que era espionado por alguém que se escondia na laranjeira existente em seu quintal, numa certa noite decidiu derrubá-la , vindo ao chão, além da árvore, a "ave noturna", que nela se aninhava para espioná-lo. A partir de então esta rua ficou conhecida como Rua da Laranjeira.

Rua Padre Agostinho - A.G.: humano / rua. Taxionomia: axiotopônimo. Histórico: Rua Padre Agostinho. Explicação: Em homenagem ao Padre Francisco Agostinho Gomes, ilustre figura brasileira, cujo mérito deveu-se além de suas ações como religioso, como também pela sua participação em questões relacionadas à Conjuração Baiana, à Revolta dos Alfaiates, etc.

Rua Santa Isabel - A.G.: humano / rua. Taxionomia: hierotopônimo: hagiotopônimo. Histórico: Rua Santa Isabel. Explicação: Em homenagem à filha de D. Pedro III, Isabel Aragão (1271-1336), rainha de Portugal. A Rainha Santa Isabel, como era conhecida, foi beatificada em1516 pelo Frei Damião. 
Rua 12 de outubro - A.G.: humano / rua. Taxionomia: historiotopônimo. Histórico: 12 de outubro. Explicação: Data em que ocorreram importantes fatos históricos no país: em 12 de outubro de 1822 o Brasil declarou oficialmente sua independência a Portugal e D. Pedro I foi proclamado Imperador do Brasil.

Rua do Passo - A.G.: humano / rua. Taxionomia: hodotopônimo. Histórico: hodotopônimo. Explicação: A expressão "Passo" é de origem portuguesa e refere-se aos passos de Jesus no caminho ao Calvário, cuja caminhada era representada tradicionalmente pelos portugueses entre os séculos XVIV e XVIII através da "Procissão do Senhor Jesus dos Passos". Essa tradição foi trazida ao Brasil pelos jesuítas no século XVI.

Rua do Bispo - A.G.: humano / rua. Taxionomia: axiotopônimo. Histórico: Rua do Bispo. Explicação: Não foi encontrado nenhum tipo de informação sobre sua possível motivação.

Praça Anchieta - A.G.: humano / praça. Taxionomia: axiotopônimo. Histórico: Praça Anchieta. Explicação: Em homenagem ao padre José de Anchieta (1534 - 1597), cujo talento como poeta e dramaturgo, o premiou como o mais antigo vulto da literatura brasileira. José de Anchieta foi beatificado em 22 de maio de 1980 na Catedral Brasílica na cidade de Salvador.

Largo do Carmo - A.G.: humano / largo. Taxionomia: axiotopônimo. Histórico: Rua nossa Senhora do Carmo, Rua do Carmo, Largo Nossa Senhora do Carmo, Largo do Carmo. Explicação: Também conhecida como rua do Carmo, foi assim nomeada por abrigar a Igreja e Convento Nossa Senhora do Carmo, conjunto arquitetônico construído no século XVI.

Largo do Cruzeiro de São Francisco - A.G.: humano / largo. Taxionomia: hierotopônimo: hagiotopônimo. Histórico: Cruzeiro de São Francisco, Largo São Francisco, Largo Cruzeiro de São Francisco. Explicação: Assim denominado em nome do cruzeiro que havia na entrada do grande Adro de São Francisco, erguido por iniciativa dos frades da Ordem Franciscana que vieram da Paraíba para ajudar os jesuítas a catequizar os índios no século XVI. 
Largo do Pedro Arcanjo - A.G.: humano / largo. Taxionomia: antropotopônimo. Histórico: Pedro Arcanjo. Explicação: Nome do protagonista da obra "Tenda dos milagres" escrita em 1969 por Jorge Amado. Nesta obra narra-se a luta de Pedro Arcanjo pela afirmação da cultura popular. Trata-se, pois de um romance fabuloso, o qual aborda questões relacionadas ao preconceito religioso e racial.

Largo de Quincas Berro D’ Água - A.G.: humano / largo. Taxionomia: antropotopônimo Histórico: Largo de Quincas Berro D’ Água. Explicação: Personagem principal do romance "A morte e a morte de Quincas Berro D' Água" do escritor baiano Jorge Amado, escrita por volta de 1958. Uma obra onde fica evidente a crítica ao comportamento burguês sem lançar mão de muito humor e ironia.

Largo de Tereza Batista - A.G.: humano / largo. Taxionomia: antropotopônimo. Histórico: Largo de Tereza Batista. Explicação: Nome da personagem do romance "Tereza Batista cansada de guerra" escrita em 1972 pelo escritor e político baiano Jorge Amado. Narra a história que Tereza Batista era uma mulher guerreira e destemida que lutava contra a submissão, a violência, a miséria e pela liberdade e pelo amor próprio.

Largo do Pelourinho - A.G.: humano / 1argo. Taxionomia: ergotopônimo/ sociotopônimo. Histórico: Parte Central de Salvador, isto é, o centro de Salvador, Largo do Pelourinho. Explicação: Neste largo ficavam as portas que fechavam a cidade: Porta de Santa Catarina, < Porta do Carmo. Foi assim nomeado por abrigar o pelourinho, coluna de pedra ou madeira utilizada para castigar escravos e criminosos.

Largo Terreiro de Jesus - A.G.: humano /largo. Taxionomia: hierotopônimo: hagiotopônimo. Histórico: Terreiro da Casa da Companhia de Jesus, Terreiro de Jesus. Explicação: Local onde em meados de 1550 foram construídos o primeiro colégio dos jesuítas em Salvador e também sua primeira 
igreja no Brasil: Igreja Nossa Senhora da Ajuda. Atualmente, no lugar onde fora construída a antiga igreja "de taipa", encontra-se a Catedral Basílica.

Conforme se pode perceber nas fichas lexicográficas, dentre os vinte topônimos do Pelourinho investigados apenas um foi motivado por taxionomia de natureza física, o qual foi representado por um fitotopônimo. Os demais foram majoritariamente motivados por taxionomias de natureza antro-cultural, assim distribuídos: 8 antropotopônimos ilustrados, geralmente, por nomes de baianos considerados importantes para o desenvolvimento da cidade; 5 hagiotopônimos ilustrados por nomes de santos e ordens religiosas de origem portuguesa tais como franciscanos, carmelitas e jesuítas; 3 axiotopônimos referentes a nomes de dignidades religiosas como Frei Vicente, Padre José Anchieta e Padre Agostinho; 1 sociotopônimo referente a nome de profissão (Rua do Bispo) cuja motivação não pode ser no momento resgatada; 1 hodotopônimo (Rua do Passo), o qual foi assim classificado por se aproximar um pouco ao que se refere esta classificação segundo Dick (1990). Aqui o termo "passo", pela sua motivação exposta anteriormente, foi associado a "caminhada", e, a "caminho" o que nas entrelinhas pode ser entendida como "via de comunicação rural ou urbana" - idéia proposta pela referida autora ; 1 historiotopônimo, representado por nome que expressa data histórica importante para o país; e 1 ergotopônimo considerando que sua motivação refere-se ao elemento da cultura material, "coluna de pedra ou madeira". Faz-se necessário esclarecer que tanto na ficha lexicográfica quanto na ficha do topônimo (item 2) a motivação Pelourinho foi também classificada como sociotopônimo, por considerá-lo o local onde escravos e criminosos eram castigados.

\section{5- Considerações finais}

Constatou-se, com esses estudos, que no topônimo Pelourinho se conserva uma história construída por um percurso de autoritarismo, dor, violência, injustiça, humilhação, gritos, lágrimas, lutas, conquistas, independência e também de orgulho. Sua motivação é alusiva a uma coluna de pedra ou de madeira erguida em praça 
pública na cidade de Salvador entre os séculos XVI e XVII pelos senhores de escravos. As taxionomias dos topônimos do Pelourinho, ou seja, as taxionomias dos seus logradouros foram motivadas, em sua maioria: (i) por nomes de ilustres figuras que, de forma muito significativa, também contribuíram para a construção de sua história, bem como para seu mérito como patrimônio histórico da cidade; (ii) por alguns designativos ligados a religiosos e a ordens religiosas portuguesas como os carmelitas, franciscanos e jesuítas e (iii) também por designativo ligado à data de importante fato histórico. O que de certa forma gerou surpresas, uma vez que, a priori, se esperou que a motivação desses signos toponímicos fosse também atrelada a nomes referentes à cultura africana pela sua ligação com o significado e, sobretudo, com a história do Pelourinho.

No processo de nomeação foram prevalecidas as taxionomias de natureza antropo-cultural, mais especificamente os antropotopônimos. Os nomes das ruas são em sua maioria motivados por nomes de importantes personagens que de fato um dia por lá passaram e minoritariamente por nomes de santos, profissão e acontecimentos. Dentre as motivações das designações dos largos, destacam-se os nomes de personagens literárias de Jorge Amado, importante político e escritor baiano, e nomes referentes a ordens religiosas.

Vale ressaltar que este trabalho caracteriza-se apenas uma versão preliminar, visto que ainda há muito a ser estudado. Posteriormente, pretende-se fazer um estudo mais "detalhado" com o objetivo de se obter possíveis respostas às indagações que não puderam aqui ser resolvidas devido à limitação dos dados colhidos, tais como a motivação da Rua do Bispo e da Rua do Passo, possíveis nomes anteriores de alguns logradouros, definição real desses logradouros, visto que alguns deles, ora são tratados como largos, ora como praças pelos historiadores, dentre outras questões, que, possivelmente, só poderão ser respondidas mediante uma pesquisa de campo. Passo crucial, segundo Dick (1990), para se garantir a veracidade de uma investigação onomástica. 


\section{Referências Bibliográficas}

DICK, M. V. P. A. Toponimia e antroponimia no Brasil. São Paulo: Coletânea de Estudos, 1990. 386 p.

FERREIRA, A. B. H. Novo Aurélio século XXI: o dicionário de língua portuguesa. São Paulo: Nova Fronteira,1999. 1834 p.

MACHADO, J. P. Dicionário etimológico de língua portuguesa. São Paulo: Livros Horizonte, 1987.1285 p.

SEABRA, M. C. T. C. A formação e a fixação da língua portuguesa em Minas Gerais: a toponímia da Região do Carmo. 2004. 368 f. Tese (Doutorado em Lingǘstica) POSLIN, Universidade Federal de Minas Gerais, Belo Horizonte. prelo) . (org.) Estudos do léxico. Belo Horizonte: FALE/UFMG, 2006. 22 f. (em

TAVARES, L. H. D. História da Babia. São Paulo: Ática, 1981. 206p.

Andrade, Allan. História de Salvador. Salvador, BA, 2005. Disponível em $<$ http://www.bahia.salvador.com.mercuri.com.br/historia2.html $>$ Acesso em 15/04/06.

Bartolomei,Marcelo.Pelourinho.BA<www.folha.uol.com.br/folha/turismo/amerei cadosul/brasil-salvador-pelourinho.smt $>$ Acesso em 10/10/06. 